\title{
Erratum to: Steroidal contraceptive use is associated with lower bone mineral density in polycystic ovary syndrome
}

\author{
Lisa J. Moran' ${ }^{1}$ R. L. Thomson ${ }^{2}$ J. D. Buckley² ${ }^{2}$ M. Noakes ${ }^{3}$ P. M. Clifton ${ }^{2}$ \\ R. J. Norman ${ }^{1,3}$ G. D. Brinkworth ${ }^{4}$
}

Published online: 29 February 2016

(c) Springer Science+Business Media New York 2016

\section{Erratum to: Endocrine (2015) 50:811-815 DOI 10.1007/s12020-015-0625-7}

In the original publication, the following sentence in the introduction and discussion should be amended from: 'Longitudinal general population studies also report inverse associations between contraceptive use and fracture risk [5]' to 'Longitudinal general population studies also report associations between contraceptive use and fracture risk [5].'

The online version of the original article can be found under doi: 10.1007/s12020-015-0625-7.

Lisa J. Moran

lisa.moran@adelaide.edu.au

1 The Robinson Research Institute, School of Paediatrics and Reproductive Health, University of Adelaide, 55 King William Road, North Adelaide, SA 5006, Australia

2 Alliance for Research in Exercise, Nutrition and Activity (ARENA), Sansom Institute for Health Research, University of South Australia, Adelaide, SA, Australia

3 Fertility SA, Adelaide, SA, Australia

4 CSIRO Food and Nutrition, Adelaide, SA, Australia 